\title{
Melanoma of the Conjunctiva Clinical TNM Finding v7
}

National Cancer Institute

\section{Source}

National Cancer Institute. Melanoma of the Conjunctiva Clinical TNM Finding v7. NCI

Thesaurus. Code C88636.

A clinical finding about one or more characteristics of melanoma of the conjunctiva, following the rules of the TNM AJCC V7 classification system. The classification applies only to conjunctival melanoma and primary acquired melanosis with atypia. In general, there should be a histologic evaluation of the tumor. The clinical assessment of a melanocytic conjunctival tumor is based on inspection, slit-lamp examination, and palpation of the regional lymph nodes. All conjunctival surfaces should be inspected and photographed (including eversion of the upper eyelid). (from AJCC 7th Ed.) 